\title{
Clinical performance of a sutureless aortic bioprosthesis: Five-year results of the $3 f$ Enable long-term follow-up study
}

\author{
Lars Englberger, MD, ${ }^{\mathrm{a}}$ Thierry P. Carrel, MD, ${ }^{\mathrm{a}}$ Mirko Doss, MD, ${ }^{\mathrm{b}}$ Jerzy Sadowski, MD, \\ Krzysztof Bartus, MD, ${ }^{\mathrm{c}}$ Friedrich F. Eckstein, MD, ${ }^{\mathrm{d}}$ Federico M. Asch, MD, ${ }^{\mathrm{e}}$ and Sven Martens, MD
}

\begin{abstract}
Objective: Sutureless valves are designed to facilitate surgical implantation, including less-invasive techniques in aortic valve replacement, by maintaining surgical precision of implantation compared with transcatheter techniques. Long-term clinical experience with sutureless valves is lacking. We report the 5-year follow-up results of an international, prospective, multicenter study evaluating the clinical performance and safety of the $3 \mathrm{f}$ Enable valve (Medtronic Inc, Minneapolis, Minn).
\end{abstract}

Methods: Between March 2007 and December 2009, 141 patients (54 male; mean age, $76.1 \pm 5.7$ years) undergoing aortic valve replacement with the $3 \mathrm{f}$ Enable valve were enrolled in 10 European sites. The mean follow-up was 2.76 years (range, 2 days to 5.1 years; total, 388.7 patient-years). Echocardiographic valvular hemodynamic and morphologic analyses were performed by an independent core laboratory.

Results: The mean systolic gradient was $10.4 \pm 4.4 \mathrm{~mm} \mathrm{Hg}$ at discharge and $7.7 \pm 4.1 \mathrm{~mm} \mathrm{Hg}$ at 5 years. The mean effective orifice area was $1.7 \pm 0.5 \mathrm{~cm}^{2}$ at discharge and $1.6 \pm 0.2 \mathrm{~cm}^{2}$ at 5 years. Freedom from all-cause and valve-related mortality was $87.6 \% \pm 2.9 \%$ and $96.8 \% \pm 1.6 \%$ at 1 year $(113$ patients at risk $)$ and $77.0 \% \pm$ $7.5 \%$ and $93.8 \% \pm 4.8 \%$ at 5 years (24 patients at risk), respectively. Six patients underwent reoperation ( 4 because of major paravalvular leakage and 2 because of endocarditis). Freedom from reoperation was $95.4 \% \pm 1.9 \%$ at 1 year and $95.4 \% \pm 6.1 \%$ at 5 years. No structural valve deterioration occurred during the follow-up period.

Conclusions: The sutureless $3 \mathrm{f}$ Enable valve represents a safe and effective treatment for aortic valve stenosis, providing an excellent hemodynamic profile. This study represents the longest follow-up study for a sutureless bioprosthesis. Sutureless valves may become an option for all patients with indicated biological aortic valve replacement. (J Thorac Cardiovasc Surg 2014;148:1681-7)

Surgical aortic valve replacement (AVR) is the standard of care for patients with severe symptomatic aortic valve stenosis. Regardless of the overall good outcomes obtained after implantation of conventional valve prostheses, alternatives have been developed, especially for high-risk patients. The introduction of transcatheter

\footnotetext{
From the Department of Cardiovascular Surgery, ${ }^{\text {a }}$ University Hospital Bern, Bern, Switzerland; Department of Thoracic and Cardiovascular Surgery, ${ }^{\mathrm{b}}$ Johann Wolfgang Goethe University, Frankfurt, Germany; Department of Cardiovascular Surgery and Transplantology, ${ }^{\mathrm{c}}$ Jagiellonian University, Krakow, Poland; Department of Cardiac Surgery, ${ }^{\mathrm{d}}$ University Hospital Basel, Basel, Switzerland; MedStar Health Research Institute, ${ }^{e}$ MedStar Washington Hospital Center, Washington, DC; and Department of Thoracic and Cardiovascular Surgery, ${ }^{\mathrm{f}}$ University Hospital Muenster, Muenster, Germany.

This study was funded by Medtronic Inc, Minneapolis, Minn.

Disclosures: Lars Englberger reports consulting fees from Medtronic and lecture fees from Medtronic and St. Jude Medical. Mirko Doss reports consulting fees from Edwards Lifesciences. Jerzy Sadowski reports grant support from Medtronic. Krzysztof Bartus reports lecture fees from Medtronic. Sven Martens reports consulting and lecture fees from Medtronic. All other authors have nothing to disclose with regard to commercial support.

Received for publication Sept 3, 2013; revisions received March 24, 2014; accepted for publication March 28, 2014; available ahead of print April 27, 2014.

Address for reprints: Lars Englberger, MD, Department of Cardiovascular Surgery,

University Hospital Bern (Inselspital), Freiburgstrasse, CH-3010 Bern,

Switzerland (E-mail: lars.englberger@insel.ch).

$0022-5223 / \$ 36.00$

Copyright (C) 2014 by The American Association for Thoracic Surgery

http://dx.doi.org/10.1016/j.jtcvs.2014.03.054
}

technology and the reemergence of sutureless bioprostheses are examples of innovations available for high-risk patients. ${ }^{1}$ Sutureless valves, approved for commercial use in Europe, are designed to allow rapid deployment combined with precise surgical implantation. ${ }^{2,3}$ Current trials evaluate the clinical impact of these valves. If the results obtained are as good as those obtained with conventional tissue valves, sutureless valves may become the first option for patients with indicated biological AVR. This would considerably increase the number of patients who may be treated with less-invasive access surgery. In addition, patients with specific anatomic conditions, such as small or calcified aortic roots, may benefit from this technology.

The first clinical results with an early design of the 3f Enable valve (Medtronic Inc, Minneapolis, Minn) were reported in $2008 .{ }^{4}$ After review of the initial data, modifications to the valve design were performed, resulting in the second generation of the device. ${ }^{5,6} \mathrm{~A}$ prospective, multicenter clinical trial enrolling patients at 10 European sites was initiated to evaluate the safety and clinical performance of the $3 \mathrm{f}$ Enable valve. One-year follow-up data from this patient group were initially published in $2011 .^{7}$ The current report presents the 5-year clinical and echocardiographic follow-up data from this study. 


\section{Abbreviations and Acronyms \\ AVR = aortic valve replacement \\ EOA $=$ effective orifice area \\ $\mathrm{EOAi}=$ indexed effective orifice area \\ NYHA $=$ New York Heart Association \\ PPM = prosthesis-patient mismatch \\ PVL = paravalvular leak \\ TAVI $=$ transcatheter aortic valve implantation \\ TTE $=$ transthoracic echocardiography}

\section{METHODS \\ Device Description}

The 3f Enable Model 6000 valve (Medtronic Inc) is made with a stentless valve of 3 equal sections of equine pericardial tissue sewn in a self-expanding nitinol support frame (Figure 1). The nitinol frame is intended to maintain the tissue valve geometry, optimize its flow area, and eliminate the potential for misplaced attachment of the commissural tabs. The properties of nitinol and the flexibility of the equine pericardial leaflets allow the device to be folded and positioned appropriately within minutes intraoperatively. On deployment, its shape and size return to the preset dimensions and the outward radial forces keep the valve fixed at the target position, preventing migration. For implantation, a single guiding suture is recommended to support placement of the valve at the level of the annulus. The polyester flange at the inflow aspect promotes tissue ingrowth, thus contributing to the long-term stabilization of the valve. Further details of the implant technique have been presented. ${ }^{5-7} \mathrm{~A}$ new model of the device was developed during the time frame of this study (to improve visualization, allow radial crimping, and improve positioning by enlarging the inflow skirt). Only 1 study site (Krakow) had an initial experience with this new model, with 10 patients receiving an implant, which constitutes a First-in-Man study, and data have not been published.

\section{Patient Population}

Patients requiring isolated AVR with or without concomitant procedures were eligible to participate. Patients requiring valve replacement other than the aortic valve and patients with previously implanted prosthetic heart valve(s) or rigid annuloplasty ring in the mitral position were excluded from the study. A total of 141 patients were enrolled in this prospective, multicenter, nonrandomized study (54 male, 87 female; mean age, $76.1 \pm 5.7$ years). Compared with a previous report, ${ }^{7} 1$ additional patient has been included in the patient population since the data were received after the previous article had been published. Participants received 3f Enable implantation between March 2007 and December 2009 in 10 European sites (Bern and Basel, Switzerland; Frankfurt, Freiburg, Muenster, Luebeck, Kiel, Germany; Krakow and Gdansk, Poland; Vienna, Austria). The study was conducted according to the applicable local and international regulatory requirements and was approved by the local ethics committee at each investigational site. A written informed consent was obtained from all participants.

\section{Procedure}

Conventional sternotomy was performed in 114 patients $(80.9 \%)$, and 27 patients $(19.1 \%)$ underwent a partial upper sternotomy. Partial aortotomy was performed in $95.7 \%$ of the patients, and full trans-section of the aorta was performed in $4.3 \%$ of the patients. After institution of cardiopulmonary bypass and cardioplegic arrest, the native aortic valve was excised under direct view. The $3 \mathrm{f}$ Enable valve was positioned and deployed in the aortic annulus. Intraoperative transesophageal echocardiogram was routinely performed to verify correct valve positioning and to assess the initial hemodynamic performance of the valve. Concomitant procedures were required in $30 \%$ of the patients. ${ }^{7}$ Mean aortic crossclamp and cardiopulmonary bypass times were $57.9 \pm 25.1$ minutes and $84.6 \pm 34.2$ minutes, respectively. The following sizes were implanted: $19 \mathrm{~mm}$ (6 patients), $21 \mathrm{~mm}$ ( 36 patients), $23 \mathrm{~mm}$ (43 patients), $25 \mathrm{~mm}$ (35 patients), $27 \mathrm{~mm}$ (16 patients), and $29 \mathrm{~mm}$ (5 patients).

\section{Follow-up}

A complete physical examination, routine chemistry panel, and transthoracic echocardiography (TTE) were performed at the time of hospital discharge, at 3 to 6 months postprocedure, at 11 to 14 months postprocedure, and annually thereafter. Hemodynamic parameters were assessed via TTE by 2-dimensional M-mode, pulsed-wave, and color-flow imaging. All echocardiograms were obtained at the recruiting centers following a study-specific protocol and interpreted by an independent core laboratory (MedStar Health Research Institute, Washington, DC), blinded to any patient information, according to the American Society of Echocardiography Guidelines. ${ }^{8}$

\section{Statistical Analysis}

Descriptive statistics are presented for baseline demographic, clinical, and operative parameters. Hemodynamic parameters are expressed as mean \pm standard deviation. Estimates for late ( $>30$ days after the procedure) adverse events are provided. Late adverse event rates were expressed as linearized rates and calculated by dividing the number of events by the length of follow-up in patient-years. Kaplan-Meier estimates and Peto standard error for cumulative survival from valve-related mortality and all-cause mortality at 1 to 5 years are presented. All analyses were conducted using SAS version 9.2 (SAS Institute Inc, Cary, NC).

\section{RESULTS}

\section{Patient and Procedure Characteristics}

Baseline demographics, most perioperative details, and initial results have been described. ${ }^{7}$ A few additional perioperative results are reported in this article, including (1) the number of sutures used- $85.1 \%$ of the patients received 1 suture, $12.1 \%$ of the patients received no sutures, $1.4 \%$ received 2 or more sutures, and suture technique data were not available for 1 patient $(0.7 \%)$; (2) the mean deployment time (10.6 \pm 8.6 minutes); and (3) procedural success (defined as the total number of implanted patients compared with the number of attempted procedures in which the valve was placed into the patient annulus): $92.5 \%$ (of the 160 attempted procedures, 148 patients received implants). As previously noted, ${ }^{7}$ we have observed a tendency to shorter crossclamp times in consecutive patients in the top 2 enrolling sites participating in this study, indicating a learning curve. For the current analysis, patients were followed for up to 5 years (total, 388.7 patient-years). The mean follow-up was 2.76 years, and the range was 2 days to 5.1 years.

\section{Hemodynamic Parameters}

Table 1 shows mean systolic and peak systolic pressure gradients, effective orifice area (EOA), and indexed EOA (EOAi) assessed by TTE at the indicated time points. The mean systolic gradient at discharge was $10.4 \pm 4.4 \mathrm{~mm}$ 


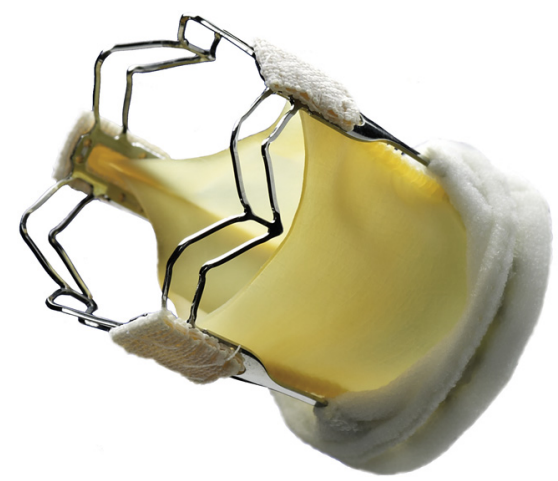

FIGURE 1. 3f Enable Model 6000 (Medtronic Inc, Minneapolis, Minn).

$\mathrm{Hg}$ and remained relatively stable to 5 years $(7.4 \pm 3.4 \mathrm{~mm}$ $\mathrm{Hg}$ ). Peak systolic gradient was $20.6 \pm 8.4 \mathrm{~mm} \mathrm{Hg}$ at discharge, decreased slightly during follow-up, and was $15.5 \pm 6.0 \mathrm{~mm} \mathrm{Hg}$ at 5 years. Mean EOA was $1.72 \pm 0.45 \mathrm{~cm}^{2}$ at discharge and $1.61 \pm 0.28 \mathrm{~cm}^{2}$ at 5 years. Mean EOAi was $0.94 \pm 0.25 \mathrm{~cm}^{2} / \mathrm{m}^{2}$ at discharge and $0.90 \pm 0.16 \mathrm{~cm}^{2} / \mathrm{m}^{2}$ at 5 years (Table 1). Table 2 shows the mean systolic pressure gradients obtained by valve size at implant and during follow-up. The mean systolic gradient values obtained at 1-year follow-up, for example, for each valve size were $11.3 \pm 1.3 \mathrm{~mm} \mathrm{Hg}(19 \mathrm{~mm}), 9.7 \pm 3.5$ $\mathrm{mm} \mathrm{Hg}(21 \mathrm{~mm}), 9.1 \pm 3.2 \mathrm{~mm} \mathrm{Hg}(23 \mathrm{~mm}), 7.1 \pm 2.2$ $\mathrm{mm} \mathrm{Hg}(25 \mathrm{~mm}), 5.6 \pm 3.0 \mathrm{~mm} \mathrm{Hg}(27 \mathrm{~mm})$, and $11.0 \mathrm{~mm} \mathrm{Hg}(29 \mathrm{~mm})$. Similar values were observed at the subsequent annual visits.

\section{Survival}

Table 3 and Figure 2 show the probability of survival after AVR with the $3 \mathrm{f}$ Enable valve during the 5-year follow-up period. Freedom from all-cause and valve-related mortality was $88 \% \pm 3 \%$ and $97 \% \pm 2 \%$ (1 year; 113 patients at risk), $84 \% \pm 3 \%$ and $95 \% \pm 2 \%$ (2 years; 99 patients at risk), $80 \% \pm 4 \%$ and $95 \% \pm 2 \%$ (3 years; 79 patients at risk), $79 \% \pm 5 \%$ and $94 \% \pm 3 \%$ (4 years; 59 patients at risk), and $77 \% \pm 8 \%$ and $94 \% \pm 5 \%$ (5 years; 24 patients at risk), respectively.

\section{Effect of Aortic Valve Replacement on New York Heart Association Functional Capacity}

The records of New York Heart Association (NYHA) classification measurements during the 5-year follow-up reflect the expected significant clinical improvement in patients after AVR. Preoperatively, $32.6 \%$ of the patients were in NYHA class I/II and $63.1 \%$ of the patients were in NYHA class III/IV; the NYHA class could not be assessed in $4.3 \%$ of the patients. Three to 6 months postprocedure, $90.4 \%$ of patients were in NYHA class I/II and $3.5 \%$ of patients were in NYHA class III/IV. In $6.1 \%$ of the patients, the NYHA class could not be assessed. These values remained similar throughout the follow-up period (Figure 3).

\section{Adverse Events}

Early adverse event rates have been reported. ${ }^{7}$ Tables 3 and 4 summarize the late adverse events ( $>30$ days postprocedure) that occurred during the course of the study. Freedom from reoperation remained stable at $95 \%$ during the follow-up period (Table 3), and the linearized rate of reoperation was $1.3 \%$ per patient-year (Table 4 ). Freedom from major paravalvular leak (PVL) remained stable at $97 \%$ during the follow-up period (Table 3), and the linearized rate of major PVL was $0.8 \%$ per patient-year (Table 4). Freedom from thromboembolic events remained at $99 \%$ during the follow-up period (Table 3). Three patients acquired prosthetic valve endocarditis during the follow-up period $(0.8 \%$ per patient-year). No structural valve deterioration was detected during the follow-up period.

Details for patients requiring reoperation are presented in Table 5. Four patients underwent reoperation because of major PVL, and 2 patients underwent reoperation because of endocarditis. During the follow-up period, 9 patients $(6.4 \%)$ had moderate regurgitation (PVL, central or indeterminate), as measured by echocardiography. No severe regurgitation was observed in the remaining patients. In addition, 10 patients were reported to have some degree of PVL perioperatively (6 patients had trace/perivalvular PVL, 3 patients had mild/perivalvular PVL, and 1 patient had moderate/both types of PVL). Of all these 10 patients, only 2 still had PVL at the 1-year follow-up visit.

\section{COMMENT}

This is the first long-term follow-up study of patients who received the sutureless $3 \mathrm{f}$ Enable valve. Clinical outcomes and hemodynamic data were satisfactory. The mean systolic pressure gradient data obtained in this 5-year follow-up

TABLE 1. Results of 3f Enable hemodynamic parameters

\begin{tabular}{|c|c|c|c|c|c|c|c|}
\hline Parameter & Discharge $(\mathrm{N}=118)$ & 3-6 mo $(\mathrm{N}=113)$ & $1 \mathrm{y}(\mathrm{N}=103)$ & $2 y(N=89)$ & $3 y(N=78)$ & 4 y $(N=57)$ & 5 y $(N=16)$ \\
\hline $\begin{array}{l}\text { Mean systolic } \\
\quad \text { gradient }(\mathrm{mm} \mathrm{Hg})\end{array}$ & $10.4 \pm 4.4(\mathrm{n}=97)$ & $9.0 \pm 3.7(\mathrm{n}=95)$ & $8.6 \pm 3.2(n=86)$ & $8.6 \pm 3.4(\mathrm{n}=72)$ & $8.7 \pm 4.3(n=64)$ & $8.5 \pm 4.3(\mathrm{n}=54)$ & $7.4 \pm 3.4(\mathrm{n}=13)$ \\
\hline $\begin{array}{l}\text { Peak systolic } \\
\quad \text { gradient }(\mathrm{mm} \mathrm{Hg})\end{array}$ & $20.6 \pm 8.4(\mathrm{n}=97)$ & $18.2 \pm 7.2(\mathrm{n}=95)$ & $16.5 \pm 6.3(\mathrm{n}=86)$ & $16.8 \pm 6.9(\mathrm{n}=72)$ & $17.5 \pm 8.7(\mathrm{n}=64)$ & $16.8 \pm 8.3(\mathrm{n}=54)$ & $15.5 \pm 6.0(n=13)$ \\
\hline $\mathrm{EOA}\left(\mathrm{cm}^{2}\right)$ & $1.72 \pm 0.45(\mathrm{n}=55)$ & $1.68 \pm 0.52(\mathrm{n}=70)$ & $1.69 \pm 0.46(\mathrm{n}=63)$ & $1.66 \pm 0.48(\mathrm{n}=49)$ & $1.66 \pm 0.36(\mathrm{n}=45)$ & $1.63 \pm 0.36(\mathrm{n}=44)$ & $1.61 \pm 0.28(\mathrm{n}=10)$ \\
\hline EOAi $\left(\mathrm{cm}^{2} / \mathrm{m}^{2}\right)$ & $0.94 \pm 0.25(\mathrm{n}=55)$ & $0.90 \pm 0.28(\mathrm{n}=70)$ & $0.92 \pm 0.25(\mathrm{n}=63)$ & $0.89 \pm 0.25(\mathrm{n}=48)$ & $0.91 \pm 0.20(\mathrm{n}=44)$ & $0.89 \pm 0.20(\mathrm{n}=41)$ & $0.90 \pm 0.16(\mathrm{n}=10)$ \\
\hline
\end{tabular}


TABLE 2. 3f Enable mean systolic gradients ( $\mathrm{mm} \mathrm{Hg}$ ) per valve size

\begin{tabular}{cccccccc}
\hline Size & Discharge & $\mathbf{3 - 6 ~ m o}$ & $\mathbf{1 ~ y}$ & $\mathbf{2 ~ y}$ & $\mathbf{3 ~ y}$ & $\mathbf{4} \mathbf{y}$ & $\mathbf{5} \mathbf{y}$ \\
\hline $19 \mathrm{~mm}$ & $18.6 \pm 6.3(\mathrm{n}=5)$ & $15.9 \pm 2.0(\mathrm{n}=5)$ & $11.3 \pm 1.3(\mathrm{n}=5)$ & $13.0 \pm 1.5(\mathrm{n}=4)$ & $11.8 \pm 0.8(\mathrm{n}=2)$ & $10.5(\mathrm{n}=2)$ \\
$21 \mathrm{~mm}$ & $11.3 \pm 3.9(\mathrm{n}=23)$ & $10.1 \pm 3.5(\mathrm{n}=23)$ & $9.7 \pm 3.5(\mathrm{n}=24)$ & $9.7 \pm 3.9(\mathrm{n}=20)$ & $10.2 \pm 4.1(\mathrm{n}=16)$ & $10.8 \pm 6.2(\mathrm{n}=13)$ & $8.0 \pm 3.5(\mathrm{n}=3)$ \\
$23 \mathrm{~mm}$ & $11.0 \pm 4.0(\mathrm{n}=29)$ & $9.5 \pm 3.1(\mathrm{n}=29)$ & $9.1 \pm 3.2(\mathrm{n}=25)$ & $8.4 \pm 3.1(\mathrm{n}=22)$ & $8.9 \pm 5.8(\mathrm{n}=22)$ & $8.1 \pm 4.2(\mathrm{n}=17)$ & $6.7 \pm 0.7(\mathrm{n}=3)$ \\
$25 \mathrm{~mm}$ & $8.2 \pm 3.3(\mathrm{n}=24)$ & $8.1 \pm 2.9(\mathrm{n}=24)$ & $7.1 \pm 2.2(\mathrm{n}=24)$ & $7.7 \pm 2.6(\mathrm{n}=18)$ & $7.7 \pm 2.5(\mathrm{n}=17)$ & $7.5 \pm 2.7(\mathrm{n}=16)$ & $7.5 \pm 5.0(\mathrm{n}=5)$ \\
$27 \mathrm{~mm}$ & $9.0 \pm 3.0(\mathrm{n}=13)$ & $5.1 \pm 1.8(\mathrm{n}=11)$ & $5.6 \pm 3.0(\mathrm{n}=7)$ & $5.1 \pm 2.3(\mathrm{n}=5)$ & $5.9 \pm 1.3(\mathrm{n}=4)$ & $5.6 \pm 2.0(\mathrm{n}=3)$ & $5.1(\mathrm{n}=1)$ \\
$29 \mathrm{~mm}$ & $6.8 \pm 2.5(\mathrm{n}=3)$ & $6.7 \pm 3.0(\mathrm{n}=3)$ & $11.0(\mathrm{n}=1)$ & $8.0 \pm 1.9(\mathrm{n}=3)$ & $6.9 \pm 1.8(\mathrm{n}=3)$ & $7.0 \pm 1.7(\mathrm{n}=3)$ & $10.3(\mathrm{n}=1)$ \\
\hline
\end{tabular}

study (Tables 1 and 2) were excellent overall and remained stable throughout the observation period. These results are consistent with previous reports on the $3 \mathrm{f}$ Enable valve that presented limited follow-up time periods. ${ }^{5-7}$ The transvalvular pressure gradients reported for other sutureless bioprostheses ${ }^{9-12}$ are similar to the values reported in this article and compare favorably with those of conventional tissue valves. ${ }^{3}$ The mean EOA values obtained in our study (Table 1) are above the recommended lower limit of $1.2 \mathrm{~cm}^{2},{ }^{13}$ and the EOAi mean values are well above the lower limit for mild/not significant $\left(0.85 \mathrm{~cm}^{2} / \mathrm{m}^{2}\right)$ prosthesis-patient mismatch (PPM). ${ }^{13,14}$ Comparable EOAi results have been reported for the Perceval S (Sorin Biomedica Cardio Srl, Saluggia, Italy), ${ }^{9}$ with slightly better EOAi values for the $3 \mathrm{f}$ Enable prosthesis in our series $\left(0.94 \pm 0.25 \mathrm{~cm}^{2} / \mathrm{m}^{2}\right.$ vs $0.85 \pm 0.23 \mathrm{~cm}^{2} / \mathrm{m}^{2}$ at discharge and $0.90 \pm 0.28 \mathrm{~cm}^{2} / \mathrm{m}^{2}$ vs $0.89 \pm 0.24 \mathrm{~cm}^{2} / \mathrm{m}^{2}$ at 3-6 months after implantation). Sutureless valves seem to offer favorable hemodynamics compared with conventional stented biological or mechanical heart valves. PPM reflects residual aortic stenosis, which is associated with lesser regression of left ventricular hypertrophy and possible impaired long-term patient outcome. The incidence of PPM in large and unselected patient cohorts have been reported up to $50 \%,{ }^{15,16}$ depending on the type of bioprostheses, thresholds of definition criteria, and other variables. ${ }^{16}$ Most studies have relied on the projected EOAi using EOA estimations obtained from previously published studies or in vitro measurements provided by the valve manufacturers. In the present study, we used individual echocardiographic EOA estimations, a more accurate approach, and the quality of data is proven by the use of an independent core laboratory.

Mean aortic crossclamp and cardiopulmonary bypass times were relatively long $(57.9 \pm 25.1$ minutes and $84.6 \pm 34.2$ minutes, respectively). The reasons for these relatively long crossclamp and cardiopulmonary bypass times are as follows: (1) This study represents a first experience, which implicates a long learning curve; (2) the implanting investigators trained other investigators (also contributing to longer learning curve); and (3) we observed a relatively high incidence of concomitant procedures $(30 \%)$. In addition, in this study less than $20 \%$ of the procedures used a minimally invasive approach. This is common for sutureless valve studies involving new centers. Investigators have preferred to gain familiarity with the technology/therapy before using a minimally invasive approach. In this study, the most experienced centers presented shorter crossclamp and cardiopulmonary bypass times $(36.8 \pm 7.7$ minutes and $54.8 \pm 11.5$ minutes, respectively).

The freedom from valve-related mortality reported $(94 \% \pm 3 \%$ at 4 years; Table 3 and Figure 2$)$ is superior to what has been reported for the Perceval S $(69.7 \%$ at 4 years). ${ }^{9}$ However, these data are difficult to compare because of different patient selection criteria and different baseline characteristics in these 2 studies, both factors of relevant confounding. Improvement in NYHA functional capacity, which was already reported at 1 year, ${ }^{7}$ remained stable over time.

TABLE 3. 3f Enable freedom from mortality and adverse events

\begin{tabular}{|c|c|c|c|c|c|}
\hline End point & $1 \mathbf{y}$ & $2 y$ & $3 \mathbf{y}$ & $4 y$ & $5 \mathbf{y}$ \\
\hline All-cause freedom from mortality & $0.88 \pm 0.03$ & $0.84 \pm 0.03$ & $0.80 \pm 0.04$ & $0.79 \pm 0.05$ & $0.77 \pm 0.08$ \\
\hline Valve-related freedom from mortality & $0.97 \pm 0.02$ & $0.95 \pm 0.02$ & $0.95 \pm 0.02$ & $0.94 \pm 0.03$ & $0.94 \pm 0.05$ \\
\hline Reoperation & $0.95 \pm 0.02$ & $0.95 \pm 0.02$ & $0.95 \pm 0.02$ & $0.95 \pm 0.03$ & $0.95 \pm 0.04$ \\
\hline Endocarditis & $0.98 \pm 0.01$ & $0.98 \pm 0.01$ & $0.98 \pm 0.02$ & $0.98 \pm 0.02$ & $0.98 \pm 0.03$ \\
\hline Thromboembolism & $0.99 \pm 0.01$ & $0.99 \pm 0.01$ & $0.99 \pm 0.01$ & $0.99 \pm 0.01$ & $0.99 \pm 0.02$ \\
\hline Nonstructural valve dysfunction & $0.91 \pm 0.03$ & $0.91 \pm 0.03$ & $0.89 \pm 0.03$ & $0.89 \pm 0.04$ & $0.89 \pm 0.06$ \\
\hline All PVL & $0.92 \pm 0.02$ & $0.92 \pm 0.03$ & $0.90 \pm 0.03$ & $0.90 \pm 0.04$ & $0.90 \pm 0.06$ \\
\hline Major PVL & $0.97 \pm 0.02$ & $0.97 \pm 0.02$ & $0.97 \pm 0.02$ & $0.97 \pm 0.02$ & $0.97 \pm 0.04$ \\
\hline Structural valve deterioration & 1.00 & 1.00 & 1.00 & 1.00 & 1.00 \\
\hline Thrombosis & 1.00 & 1.00 & 1.00 & 1.00 & 1.00 \\
\hline Major hemorrhage & $0.91 \pm 0.03$ & $0.90 \pm 0.03$ & $0.90 \pm 0.03$ & $0.90 \pm 0.04$ & $0.90 \pm 0.06$ \\
\hline
\end{tabular}

$P V L$, Paravalvular leak. 


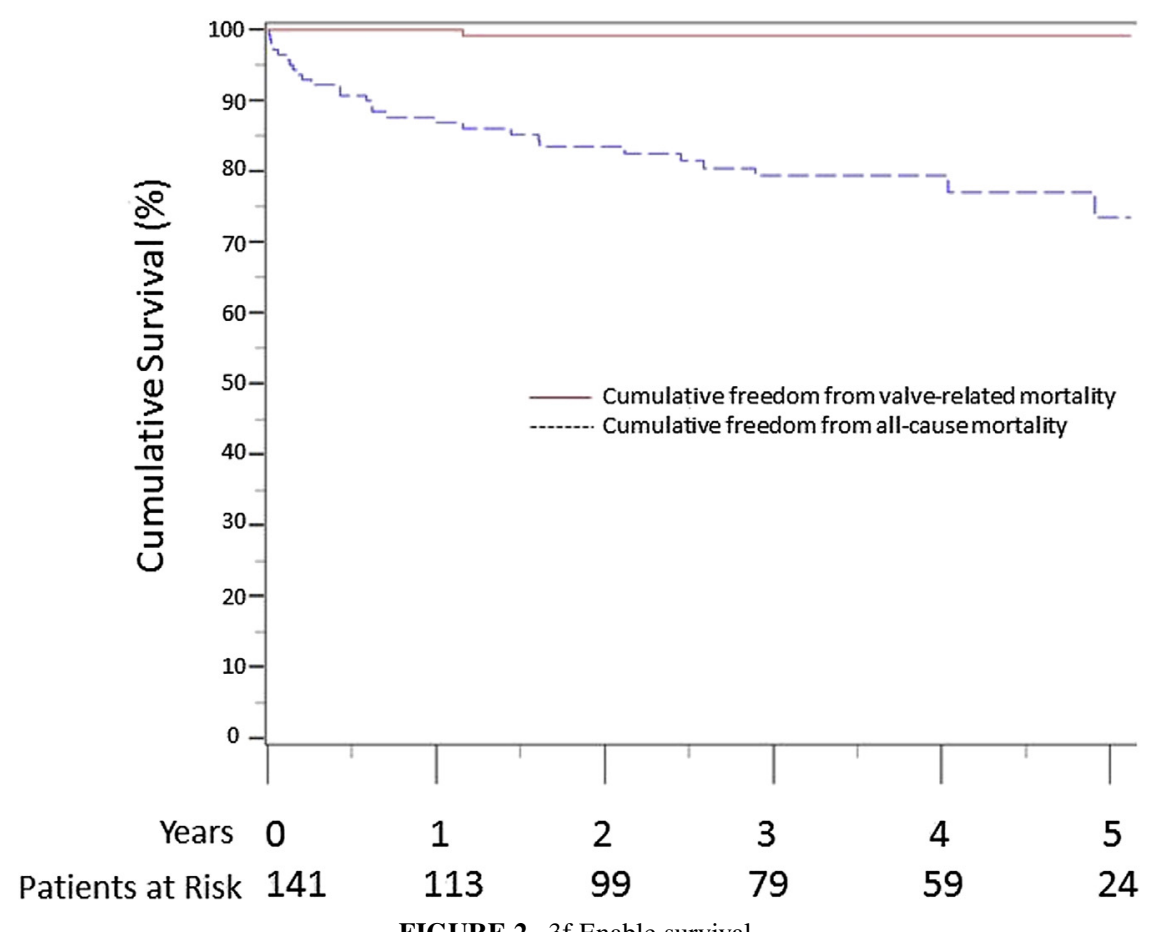

The overall rate of adverse events was low. Of note, there was no structural deterioration in a reported cumulative time of 388.8 patient-years. In addition, no thromboembolic event was reported, and the rates of prosthetic valve endocarditis and major hemorrhage were well in or below the expected range (Table 3). Also of note, there were no relevant differences among centers that could be linked to any late results (which also is due to the unequal distribution of patients among the sites).

Because of the concept and the intrinsic design of such valves, some concerns initially existed about a possibly elevated risk of PVL after sutureless valves implantation.,
The incidence of PVL for the Perceval S has been similar to what has been observed for the $3 \mathrm{f}$ Enable, and both have been numerically better than what has been reported for the Trilogy valve (Arbor Surgical Technologies Inc, Irvine, Calif) ${ }^{7-12}$ Four patients ( 1 early and 3 late) had major PVL postoperatively, requiring reoperation in this study $(2.8 \%$ overall incidence). In the most recent Perceval S report, ${ }^{9} 4 \%$ of the patients had PVL and all those patients required reoperation $(9 / 208$ patients).

In our study, $6.4 \%$ of the patients had moderate regurgitation, detected in at least 1 follow-up TTE. No severe regurgitation was observed. Paravalvular

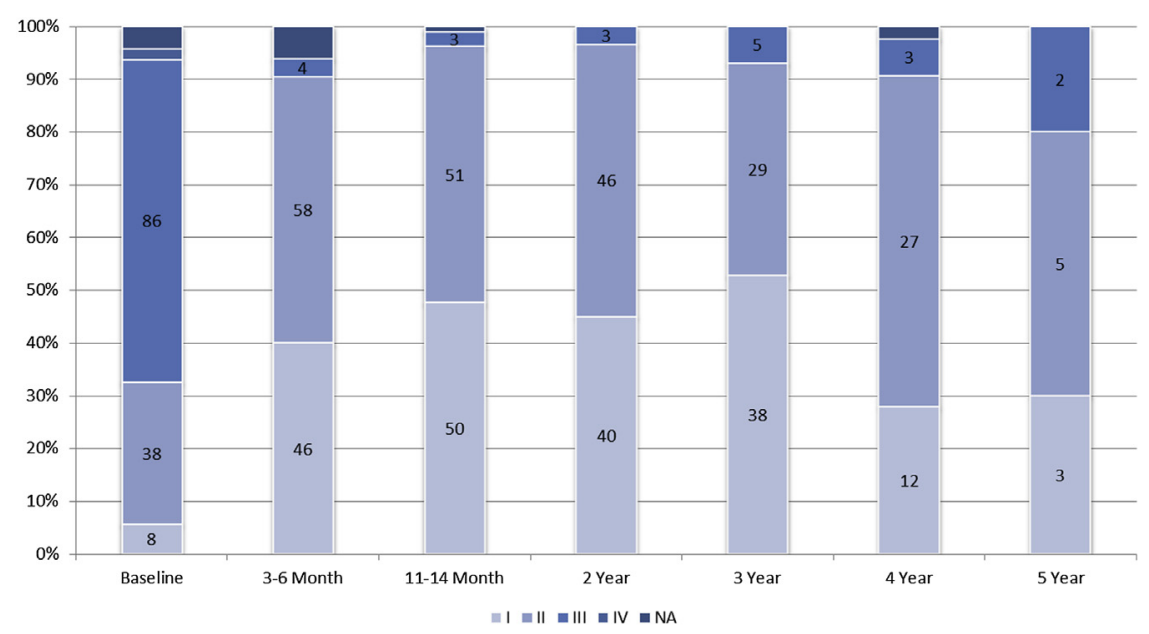

FIGURE 3. 3 f Enable NYHA class across visits. $N A$, Not available. 
TABLE 4. 3f Enable late adverse events

\begin{tabular}{lcc}
\hline \multicolumn{1}{c}{ Complication } & N (linearized rate) & CI \\
\hline All-cause mortality & $23(6.1 \%)$ & $(4.0-9.2)$ \\
$\quad$ Valve-related death & $6(1.6 \%)$ & $(0.7-3.5)$ \\
Reoperation & $5(1.3 \%)$ & $(0.6-3.2)$ \\
Endocarditis & $3(0.8 \%)$ & $(0.3-2.5)$ \\
Thromboembolism & $0(0.0 \%)$ & - \\
Nonstructural valve dysfunction & $7(1.9 \%)$ & $(0.9-3.9)$ \\
$\quad$ All PVL & $6(1.6 \%)$ & $(0.7-3.5)$ \\
$\quad$ Major PVL & $3(0.8 \%)$ & $(0.3-2.5)$ \\
Structural valve deterioration & $0(0.0 \%)$ & - \\
Thrombosis & $0(0.0 \%)$ & - \\
All hemorrhage/bleeding & $5(1.3 \%)$ & $(0.6-3.2)$ \\
$\quad$ Major hemorrhage & $5(1.3 \%)$ & $(0.6-3.2)$ \\
$\quad$ Bleeding/anticoagulant & $3(0.8 \%)$ & $(0.3-2.5)$ \\
$\quad$ Bleeding/no anticoagulant & $2(0.5 \%)$ & $(0.1-2.1)$ \\
\hline
\end{tabular}

$C I$, Confidence interval; $P V L$, paravalvular leak.

regurgitation is, comparatively, a more frequent drawback after transcatheter aortic valve implantation (TAVI) because of incomplete annular sealing. ${ }^{17-19}$ Moderate or moderate/severe regurgitation has been reported in TAVI studies from $7 \%$ to $24 \%$ of the patients, and severe regurgitation is commonly reported at up to $1 \%$ to $2 \%$ of the patients. ${ }^{20,21} \mathrm{~A}$ recent report ${ }^{22}$ compared, in a propensity-matched analysis, patients undergoing transapical TAVI with patients undergoing sutureless AVR with the Perceval $\mathrm{S}$ valve. Those investigators found a significantly higher rate of (at least mild) PVL after TAVI compared with sutureless AVR $(44.7 \%$ vs $15.8 \%, P<.001)$. Compared with these data, the findings reported with the $3 \mathrm{f}$ Enable valve are more satisfying, even if the rate of PVL is still higher than after conventional AVR. ${ }^{23}$ Residual aortic regurgitation has been shown to be an independent predictor of short- and long-term mortality after TAVI, ${ }^{18,24,25}$ as well as after conventional AVR. ${ }^{23}$ The correlation between postprocedural moderate-to-severe PVL and worse outcome is understandable. ${ }^{18}$ However, it is not yet clarified whether mild PVL after AVR is more a surrogate marker for sicker patients (advanced aortic valve disease) or really a causative for elevated mortality in the mid- and long-term follow-up.

Patients who underwent reoperation for major PVL had their valve explanted within the first 6 months (range, 5-164 days) after index surgery, and in all 4 patients central or indeterminate regurgitation was already observed on discharge TTE (Table 5). In contrast, no patient underwent reoperation if the absence of any regurgitation was documented at discharge. We conclude that regurgitation should not be accepted after sutureless valve implantation, neither in the operation room nor during index hospitalization. ${ }^{26}$ If a moderate PVL is detected until discharge, evaluation should be made for early reoperation. Major PVL seems to occur more often in larger valve sizes; 3 of 4 patients $(75 \%)$ with major PVL had received a 27-mm 3f Enable prosthesis, although a valve size $27 \mathrm{~mm}$ or greater was implanted in only 21 of 141 patients $(15 \%)$ in the entire study group. However, if this is an inherent problem with larger valve sizes remains hypothetical because we have investigated only a limited number of patients.

Potential advantages of sutureless over percutaneous valves include lower rates of stroke, thromboembolism and permanent pacemaker implantation, lack of peripheral access complications, and concerns that retention of calcific aortic debris after TAVI is not appropriate in younger patients and patients with lower-risk surgical profile. , $, 7,27^{-1}$

The combination of sutureless valves and less-invasive approaches (used with $19.1 \%$ of the patients in this study) has been described in the literature. ${ }^{28-30}$ The use of less-invasive procedures has gained increasing acceptance and will probably expand further in the future. This approach offers an additional platform for the implantation of the $3 \mathrm{f}$ Enable valve and other sutureless valves.

\section{CONCLUSIONS}

Our report demonstrates that the $3 \mathrm{f}$ Enable sutureless valve represents a safe and effective treatment for aortic valve stenosis and shows excellent hemodynamic results within a 5-year follow-up period.

The authors thank the other participating investigators from the "ATS 3f Enable Aortic Bioprosthesis Model 6000" study for their contribution to the trial: Stefan Sorg, MD, Department of Cardiovascular Surgery, Albert-Ludwigs University, Freiburg, Germany; Hans H. Sievers, MD, Department of Cardiac and Thoracic Vascular Surgery, University Clinic of Schleswig-Holstein,

TABLE 5. 3f Enable reoperation details

\begin{tabular}{|c|c|c|c|c|c|c|c|}
\hline Procedure & Approach & Gender & Age (y) & Valve size (mm) & $\begin{array}{c}\text { Days after } \\
\text { index surgery }\end{array}$ & $\begin{array}{c}\text { Regurgitation } \\
\text { at discharge }\end{array}$ & Adverse event \\
\hline Isolated AVR & Mini-sternotomy & $\mathrm{F}$ & 59 & 27 & 132 & Mild & Major PVL \\
\hline Isolated AVR & Sternotomy & M & 74 & 27 & 96 & Mild & Valve endocarditis \\
\hline Isolated AVR & Sternotomy & M & 73 & 27 & 5 & Moderate & Major PVL \\
\hline Combined & Sternotomy & M & 82 & 27 & 66 & Mild & Major PVL \\
\hline Isolated AVR & Sternotomy & M & 74 & 25 & 126 & Unknown & Valve endocarditis \\
\hline Isolated AVR & Sternotomy & $\mathrm{F}$ & 67 & 23 & 164 & Mild & Major PVL \\
\hline
\end{tabular}

$A V R$, Aortic valve replacement; $P V L$, paravalvular leak. 
Campus Luebeck, Luebeck, Germany; Jochen Cremer, MD, Department of Cardiovascular Surgery, University Medical Center of Schleswig-Holstein, Campus Kiel, Kiel, Germany; Jan Rogowski, MD, Department of Cardiovascular Surgery, Medical University of Gdansk, Gdansk, Poland; Marek Ehrlich, MD, Department of Cardiac Surgery, Medical University, Vienna, Austria; Ravi Pillai, MD, Consultant Cardiac Surgeon, Durdans Hospital, Colombo, Sri Lanka; and Christian Schlensak, MD, Department of Cardiovascular and Thoracic Surgery, University Hospital, Tuebingen, Germany. The authors thank Ricardo de Medeiros and Myriam Demas, Medtronic employees, for preparing all tables and figures, and providing copyediting assistance; Cathy Zeng, Medtronic employee, for performing all statistical analyses for this report and ensuring the accuracy of the data presented; and Jessica Halverson and Christian Vanoni, for managing the study.

\section{References}

1. Wendt D, Thielmann M, Pizanis N, Jánosi RA, Kamler M, Jakob H. Sutureless aortic valves over the last 45 years. Minim Invasive Ther Allied Technol. 2009; 18:122-30.

2. Carrel T, Englberger L, Stalder M. Recent developments for surgical aortic valve replacement: the concept of sutureless valve technology. Open J Cardiol. 2013; doi:10.13055/ojcar_4_1_1.130112.

3. Zannis K, Folliguet T, Laborde F. New sutureless aortic valve prosthesis another tool in less invasive aortic valve replacement. Curr Opin Cardiol. 2012;27:125-9.

4. Wendt D, Thielmann M, Buck T, Jánosi RA, Bossert T, Pizanis N, et al. First clinical experience and 1-year follow-up with the sutureless 3F-Enable aortic valve prosthesis. Eur J Cardiothorac Surg. 2008:33:542-7.

5. Aymard T, Kadner A, Walpoth N, Göber V, Englberger L, Stalder M, et al. Clinical experience with the second-generation $3 f$ Enable sutureless aortic valve prosthesis. J Thorac Cardiovasc Surg. 2010;140:313-6.

6. Martens S, Ploss A, Sirat S, Miskovic A, Moritz A, Doss M. Sutureless aortic valve replacement with the 3 f Enable aortic bioprosthesis. Ann Thorac Surg. 2009;87:1914-7.

7. Martens S, Sadowski J, Eckstein FS, Bartus K, Kapelak B, Sievers HH, et al. Clinical experience with the ATS $3 \mathrm{f}$ Enable ${ }^{\circledR}$ Sutureless Bioprosthesis. Eur J Cardiothorac Surg. 2011;40:749-55.

8. Zoghbi WA, Chambers JB, Dumesnil JG, Foster E, Gottdiener JS, Grayburn PA, et al. Recommendations for evaluation of prosthetic valves with echocardiography and Doppler ultrasound. J Am Soc Echocardiogr. 2009;22:975-1014.

9. Folliguet TA, Laborde F, Zannis K, Ghorayeb G, Haverich A, Shrestha M. Sutureless Perceval aortic valve replacement: results of two European centers. Ann Thorac Surg. 2012;93:1483-8.

10. Flameng W, Herregods MC, Hermans H, Van der Mieren G, Vercalsteren M, Poortmans G, et al. Effect of sutureless implantation of the Perceval S aortic valve bioprosthesis on intraoperative and early postoperative outcomes. J Thorac Cardiovasc Surg. 2011;142:1453-7.

11. Breitenbach I, Wimmer-Greinecker G, Bockeria LA, Sadowski J, Schmitz C, Kapelak B, et al. Sutureless aortic valve replacement with the Trilogy Aortic Valve System: multicenter experience. J Thorac Cardiovasc Surg. 2010;140: 878-84.

12. Kocher AA, Laufer G, Haverich A, Shrestha M, Walther T, Misfeld M, et al. One-year outcomes of the Surgical Treatment of Aortic Stenosis with a Next Generation Surgical Aortic Valve (TRITON) trial: a prospective multicenter study of rapid-deployment aortic valve replacement with the Edwards Intuity Valve System. J Thorac Cardiovasc Surg. 2013;145:110-6.

13. Pibarot P, Dumesnil JG. Prosthesis-patient mismatch: definition, clinical impact and prevention. Heart. 2006;92:1022-9.

14. Pibarot P, Dumesnil JG. Doppler echocardiographic evaluation of prosthetic valve function. Heart. 2012;98:69-78.

15. Head SJ, Mokhles MM, Osnabrugge RL, Pibarot P, Mack MJ, Takkenberg JJ, et al. The impact of prosthesis-patient mismatch on long-term survival after aortic valve replacement: a systematic review and meta-analysis of 34 observational studies comprising 27186 patients with 133141 patient-years. Eur Heart J. 2012;33:1518-29.

16. Bleiziffer S, Ali A, Hettich IM, Akdere D, Laubender RP, Ruzicka D, et al Impact of the indexed effective orifice area on mid-term cardiac-related mortality after aortic valve replacement. Heart. 2010;96:865-71.

17. Généreux P, Head SJ, Wood DA, Kodali SK, Williams MR, Paradis JM, et al Transcatheter aortic valve implantation: 10-year anniversary. Part II: clinical implications. Eur Heart J. 2012;33:2399-402.

18. Généreux P, Head SJ, Hahn R, Daneault B, Kodali S, Williams MR, et al Paravalvular leak after transcatheter aortic valve replacement: the new Achilles' heel? A comprehensive review of the literature. J Am Coll Cardiol. 2013 Jan 25 [Epub ahead of print].

19. Gotzmann M, Lindstaedt M, Mügge A. From pressure overload to volume overload: aortic regurgitation after transcatheter aortic valve implantation. Am Heart J. 2012;163:903-11.

20. Kodali SK, Williams MR, Smith CR, Svensson LG, Webb JG, Makkar RR, et al. PARTNER Trial Investigators. Two-year outcomes after transcatheter or surgical aortic-valve replacement. N Engl J Med. 2012;366:1686-95.

21. Gurvitch R, Wood DA, Tay EL, Leipsic J, Ye J, Lichtenstein SV, et al. Transcatheter aortic valve implantation: durability of clinical and hemodynamic outcomes beyond 3 years in a large patient cohort. Circulation. 2010;122:1319-27.

22. D’Onofrio A, Messina A, Lorusso R, Alfieri OR, Fusari M, Rubino P, et al Sutureless aortic valve replacement as an alternative treatment for patient belonging to the "gray zone" between transcatheter aortic valve implantation and conventional surgery: a propensity-matched, multicenter analysis. $J$ Thorac Cardiovasc Surg. 2012;144:1010-6.

23. Sponga S, Perron J, Dagenais F, Mohammadi S, Baillot R, Doyle D, et al. Impact of residual regurgitation after aortic valve replacement. Eur J Cardiothorac Surg. 2012:42:486-92.

24. Tamburino C, Capodanno D, Ramondo A, Petronio AS, Ettori F, Santoro G, et al Incidence and predictors of early and late mortality after transcatheter aortic valve implantation in 663 patients with severe aortic stenosis. Circulation. 2011;123:299-308

25. Gotzmann M, Pljakic A, Bojara W, Lindstaedt M, Ewers A, Germing A, et al Transcatheter aortic valve implantation in patients with severe symptomatic aortic valve stenosis-predictors of mortality and poor treatment response. Am Heart J. 2011;162:238-45.

26. Eichstaedt HC, Easo J, Härle T, Dapunt OE. Early single-center experience in sutureless aortic valve implantation in 120 patients. J Thorac Cardiovasc Surg. 2014;147:370-5

27. Suri RM, Thalji NM. Minimally invasive heart valve surgery: how and why in 2012. Curr Cardiol Rep. 2012;14:171-9.

28. Martens S, Zierer A, Ploss A, Sirat S, Miskovic A, Moritz A, et al. Sutureless aortic valve replacement via partial sternotomy. Innovations (Phila). 2010;5: $12-5$.

29. Tabata M, Umakanthan R, Cohn LH, Bolman RM III, Shekar PS, Chen FY, et al Early and late outcomes of 1000 minimally invasive aortic valve operations. Eur J Cardiothorac Surg. 2008;33:537-41.

30. Suri RM, Burkhart HM, Schaff HV. Robot-assisted aortic valve replacemen using a novel sutureless bovine pericardial prosthesis: proof of concept as an alternative to percutaneous implantation. Innovations. 2010;5:419-23. 